\title{
Coenzyme Complex Decreased Cardiotoxicity When Combined with Chemotherapy in Treating Elderly Patients with Gastrointestinal Cancer
}

\author{
Hai-Yan Zhang, Xiang Lu*
}

\begin{abstract}
Objective: To investigate the effect of coenzyme complex on decreasing cardiotoxicity in elderly patients with gastrointestinal cancer who were treated by chemotherapy. Methods: From September 2011 to February 2015, we recruited 54 elderly (with more than 70 years of age) patients with gastrointestinal cancer, with advanced disease. Then treated with chemotherapy combined with or without coenzyme complex. After two cycles of treatment, the effect of coenzyme complex on decreasing cardiotoxicity were evaluated. Results: Chemotherapy was combined with coenzyme complex in 32 patients (22man, 10 woman; median age: 74 years, range: 70-87 years) without coenzyme complex in 22 patients (15man, 7 woman; median age: 73 years, range: $70-80$ years) with gastrointestinal cancer. Cardiac event was significantly lower in patients treated with chemotherapy combined with coenzyme complex $(p<0.01)$. Conclusions: Coenzyme Complex decreased cardiotoxicity when combined with chemotherapy in treating elderly patients with gastrointestinal cancer.
\end{abstract}

Keywords: Coenzyme complex - cardiotoxicity - gastrointestinal cancer

Asian Pac J Cancer Prev, 16 (9), 4045-4049

\section{Introduction}

It is estimated that the incidence and prevalence of cancer are increasing in the elderly populations in the world and more than $60 \%$ of cancers were diagnosed among persons of more than 65 years of age (Yancik et al., 1997; Siegel et al., 2012; Liu et al., 2013; Weiet al., 2013; Xu et al., 2013; Liuet al., 2014). Because aging is linked with a progressive reduction in functional status and with an increased prevalence of chronic diseases and of debilitating conditions and this linkage leads to increased susceptibility to diseases and to stress, resulting in an increased risk of death, the treatment in elderly patients with cancer should be specially arranged (Theou et al., 2014). Gastric cancer is a disease of elderly people. The number of patients aged $\geq 70$ years with gastric cancer is increasing in China. Regarding colorectal cancer, almost $75 \%$ of patients are more than 65 years of age and the median age at diagnosis is 70 years (Köhne et al., 2008). Despite this, elderly patients are typically excluded in clinical trials, with less than $10 \%$ of patients enrolled in cancer clinical trials included patients more than 70 years of age (Labianca et al., 2010). Thus, for elderly people, chemotherapy for gastric and colorectal cancer remains the combination of standard chemotherapy (including 5-Fu, oxaliplatin, and irinotecan) and targeted therapies (including cetuximab and bevacizumab) and is considered as guideline base regimens that is believed to be associated with an increasing of survival time. For patients with gastric cancer, these combinations typically also include 5-Fu/epirubicin (pirarubicin)/oxaliplatin (cisplatin), 5-Fu/ paclitaxel/oxaliplatin, 5-Fu/docetaxel/oxaliplatin, 5-Fu/ paclitaxel/cisplatin and 5-Fu/docetaxel/cisplatin, etc. For patients with colorectal cancer, the addition of irinotecan to bolus 5-fluorouracil/leucovorin (5-FU/LV) increased median survival from 12 to 14.8 months (Saltz et al., 2000) for patients with an advanced disease. Doublets such as irinotecan plus infusional 5-FU/LV (FOLFIRI) or oxaliplatin plus infusional 5-FU/LV (FOLFOX) prolonged median survival to more than 20 months (de Gramont et al., 2000; Douillard et al., 2000; Goldberg et al., 2004; K“"ohne et al., 2005). Nevertheless, many elderly patients failed to tolerate treatment due to chemotherapyrelated complication that increases with age, especially cardiotoxicity. One of the basic chemotherapeutic agents in these regimens is 5-Fu. A severe side effect to $5-\mathrm{Fu}$ based treatment is cardiotoxicity, which often presents as myocardial ischemia, and to a lesser extent cardiac arrhythmias, hyper- and hypotension, left ventricular dysfunction, cardiac arrest and sudden death (Rezkalla et al., 1989; Meyer et al., 1997; Meydan et al., 2005; Ng et al., 2005; Kosmas et al., 2008; Polk et al., 2013). The incidence of 5-FU-induced cardiotoxicity varies between $0-35 \%$ and may depend on dose, cardiac comorbidity and schedule of chemotherapy (Meyer et al., 1997; Kosmas et al., 2008; Polk et al., 2013). Another concern 
is anthracyclines, and epirubicin and pirarubicine are now seldom used for the management of patients in this setting. In case of gastric cancer, approximately $25 \%$ of patients may be eligible to receive trastuzumab, a monoclonal antibody that may cause a generally reversible decline in ejection fraction. Thus, how to control side effects of chemotherapy, especially cardiotoxicity, in elderly patients with gastrointestinal cancers are a research focus in clinical practice.

According to this background, we hypothesize that coenzyme complex could decrease cardiotoxicity when combined with chemotherapy in treating elderly patients with gastrointestinal cancer.

\section{Materials and Methods}

\section{Patients}

All patients were required to be pathologically/ cytologically diagnosed with gastric or colorectal cancer and received chemotherapy in Jiangsu Cancer Hospital \& Research Institute from September 2011 to February 2014. Eligibility criteria were as follows: (1) to be aged more than 70 years; (2) to have a score of karnofsky performance status (KPS) $\geq 70$; (3) to sign an informed consent before treatment; . (4) to have blood test results meet the following requirements: white blood cell count $>3.0 \times 10^{9} / 1$ and platelet count $>150 \times 10^{9} / 1$, bilirubin and transaminases $<1.5$ times the upper normal limit and creatinine leval $<1.5$ times the upper normal limit; (5) to have a LVEF considered normal according to the lower limit of the normal range. Patients were excluded from this study: (1)failed to complete two cycles of chemotherapy; (2)with any serious medical or psychiatric condition; (3)to have experienced a myocardial infarction in the previous year, a history of uncontrolled angina pectoris, or symptomatic valvular heart disease; (4) suffer from other malignancies at the same time. All patients were divided into two groups, chemotherapy with (Group A) or without enzyme complex (Group B).

\section{Monitoring}

Prior to chemotherapy, all eligible patients underwent cardiac assessment, tumor assessment, physical examination, evaluation of medical history and performance status (PS) according to KPS criteria, and routine blood tests.

\section{Treatment}

Coenzyme complex was given from the first dose for a minimum of two cycles. Patients with stable disease, or better, continued their assigned treatment for a maximum of six cycles. Appropriate supportive therapies, including hematopoietic growth factors, were given according to the condition of each patient. All patients received the chemotherapy regimen based on a routine arrangement, after informed consent was signed. The doses of chemotherapy were reduced by $50 \%$ in case of a bilirubin value between 1.5 and $3.0 \mathrm{mg} / \mathrm{dl}$ and by $75 \%$ for a value more than $3.0 \mathrm{mg} / \mathrm{dl}$. Treatment was discontinued if patients developed progressive disease, clinical signs of $\mathrm{CHF}$, experienced a cardiac event or unacceptable toxicities.

Thirty minutes before chemotherapy, $4 \mathrm{ml}$ coenzyme complex with $250 \mathrm{ml} 5 \%$ GS was infused intravenously over approximately $45 \mathrm{~min}$. Treatment cycles were repeated every 3 weeks provided the neutrophil count was $\geq 1.5 \times 10^{9} / 1$ and the platelet count was $\geq 100 \times 10^{9} / 1$, otherwise chemotherapy were delayed and coenzyme complex was continued until hematological recovery. Hematology, serum chemistries, performance status and adverse events graded according to Common Toxicity Criteria (CTC) version 2.0 were assessed before each cycle and at the first follow-up visit (within 30-45 days after treatment completion). Cardiac evaluation consisted of physical examination, blood pressure measurements, and ECG. Cardiac assessments were performed with every cycle during chemotherapy. Chemotherapy was based on previous records, e.g., LV $200 \mathrm{mg} / \mathrm{m}^{2} /$ day was administered intravenously for $2 \mathrm{~h}$; a bolus IV of 5 -FU $400 \mathrm{mg} / \mathrm{m}^{2}$ was administered, which was followed by intravenous administration of $5-\mathrm{FU} 600 \mathrm{mg} / \mathrm{m}^{2}$ continuously for the remaining $22 \mathrm{~h}$, continued for 2 days; oxaliplatin $85 \mathrm{mg} / \mathrm{m}^{2}$ was infused for $2 \mathrm{~h}$ only on day 1. A prophylactic antiemetic and sufficient fluid were infused on days 1 and 2 of chemotherapy. This regimen was administered every 2 weeks.

\section{Evaluation of a cardiac event}

The primary efficacy parameter was the incidence of cardiac events. A cardiac event was defined as: the appearance of clinical signs of cardiac insufficiency (graded according to the New York Heart Association classification of cardiac status) and ECG manifestation. All symptoms of toxicity were evaluated according to the Common Toxicity Criteria (CTC) version 2.0.

\section{Statistical Analysis}

Statistical comparison between two treatment groups for categorical variables was made with Pearson's chisquare test or Fisher's exact test, as appropriate.

\section{Results}

\section{Patients}

There were 32 patients (22man, 10 woman; median age: 74 years, range: 70-87 years) in Group A and 22 (15man, 7 woman; median age: 73 years, range: $70-80$ years) in Group B. Demographic factors and disease status of patients in Group A and B were comparable at baseline. The majority of patients had a KS PS of more than 70. All chemotherapy administered to Group A with coenzyme and Group B contained 5-Fu. Paclitaxel and docetaxel were prescribed only in patients with gastric cancer. Primary reasons for premature withdrawal from the study were those who did not tolerate chemotherapy.

\section{Evaluation of cardiac protection}

Significantly fewer cardiac events occurred in the coenzyme complex group compared with the control group $(P<0.05)$. Nine patients receiving coenzyme complex experienced a cardiac event versus 15 patients in Group B. 
DOI:http://dx.doi.org/10.7314/APJCP.2015.16.9.4045

Coenzyme Complex Decreased Cardiotoxicity When Combined with

\section{Evaluation of safety}

The majority of patients experienced at least one adverse event, with the most common being nausea, vomiting, neutropenia, leucopenia, anemia, diarrhea and peripheral neuropathy. The incidence of adverse events was comparable between the two groups with the possible exceptions of peripheral neuropathy, which appeared more frequent in patients with gastric cancer who were treated with a combination of 5-Fu, paclitaxel and oxaliplatin. Stomatitis appeared more frequently in patients with colorectal cancer who were treated with FOLFOX regimen. Neutropenia was the most common grade 3/4 toxicity, occurring in approximately one-third of patients with in either group. Few patients in Group A than Group B experienced at least one serious adverse event; the incidence was similar for both groups, although febrile neutropenia appeared to be slightly higher among coenzyme complex-treated patients. There were no differences between groups with respect to biochemical or hematological laboratory measurements. No treatment related death occurred in both groups.

\section{Discussion}

Epirubicine, adriamycine and pirarubine are the main anthracyclines prescribed to treat gastric cancer. But, cardiotoxicity limits their clinical use, because of the association with myocardial injury (Lipshultz et al., 1997). Previous researches suggested that very low dose of anthracycline could cause subclinical cardiac abnormalities (Ewer et al., 1984; Speyer et al., 1988; Speyer et al., 1992) and these cardiac damages could be irreversible and potentially progressive with subsequent dose of anthracycline. Impaired cardiac function can result in clinically overt disease manifest as congestive heart failure, which can occur in adult patients at any stage during or following treatment. The development of clinical signs of heart failure may result in severe, disabling morbidity and increased mortality. Thus, anthracyclines are seldom used at present in the treatment of elderly patients with gastric cancer in China.

Paclitaxel and docetaxel are the main component of combined chemotherapy for patients with gastric cancer. Paclitaxel and docetaxel could cause cardiac toxicity at an incidence rate of $0.5 \%$ in the form of sub-acute or acute bradycardia, heart block, and atrial or ventricular arrhythmias (Untch et al., 2010). Paclitaxel combined with anthracyclines could reduce anthracycline elimination, foster anthracycline-associated cardiotoxicity, and especially, induce congestive heart failure (Holmes et al., 1996; Untch et al., 2010). Regarding docetaxel, it exerts the actions by stabilising microtubules, and it induces contractile dysfunction and induces heart failure in patients with left ventricular dysfunction (Shimoyama et al., 2001).

Another important and frequently used chemotherapeutic agent in treating patients with gastric and colorectal cancer is 5-Fu and its analogues. A severe side effect to 5-Fu and its analogues is cardiotoxicity. Animal studies suggested that 5-Fu induced pathological changes in the myocardium as well as on the endothelium
(Kinhult et al., 2003). In the myocardium, the damages were supposed to depend on the dose of 5-Fu used, because high doses cause more significant injuries (Tsibiribi et al., 2006). The mechanism of 5-Fu induced cardiotoxicity could also involve oxidative stress (Lamberti et al., 2012). Reactive oxygen species, i.e.., superoxide anions are under normal physiological conditions cleared by antioxidant defense systems, e.g., sodium oxide dismutase and glutathione. Similarly, Kinhult et al. (Kinhult et al., 2003) suggested that 5-Fu induced damage to the arterial endothelium may be due to generation of free radicals, resulting in lipid peroxidation. Their demonstration of a protective effect of probucol on arterial endothelium in rabbits treated with 5-FU supports this statement. In patients with acute 5 -Fu induced cardiotoxicity, the mechanism was hypothesized to be vasospasm that caused myocardial ischemia (Kim et al., 2012; Ozturk et al., 2013). And, vasospasm of coronary artery was visualized during coronary angiography in some cases (Luwaert et al., 1991; Shoemaker et al., 2004; Alter et al., 2006). Peripherally, vasoconstriction of the brachial artery was observed immediately after 5-Fu injection (Sudhoff et al., 2004; Salepci et al., 2010). Thus, it is also hypothesized that vasoconstriction detected peripherally after 5-Fu injection occurs in the coronary arteries as well. While vasoconstriction is observed immediately after 5-Fu injection, clinical cardiotoxicity often presents at the end of infusion, or hours to days later or may occur after several series of 5-Fu or its analogues (Polk et al., 2013). Most important, high plasma levels of endothelin-1 observed by Thyss et al. in 5-Fu treated patients, and especially in patients experiencing 5-Fu induced cardiotoxicity, supported this hypothesis (Thyss et al., 1992). Endothelin-1 is a potent vasoconstrictor produced by endothelial cells, cardiomyocytes and cardiac fibroblasts (Levin et al., 1995; Khimji et al., 2010). Endothelin-1 is known to have a regulatory role in coronary vascular resistance and myocardial capillary blood flow in coronary artery diseases (Kinlay et al., 2001; MacCarthy et al., 2001; Khimji et al., 2010).

Our current study suggested that cardiac event was significantly lower in patients treated with chemotherapy combined with coenzyme complex. The main component of coenzyme complex prescribed in our study is coenzyme A, glutathione and ATP. We supposed the explanation could involve several points. First, coenzyme is a substance which enhances cell membrane stabilization and mitochondrial energy production, and also has antioxidant effects (Shekelle et al., 2003; Molyneux et al., 2008). Recent studies suggested the role of oxidative stress and inflammation in the treatment of heart failure (Shekelle et al., 2003; Molyneux et al., 2008). Second, glutathione is the major intracellular antioxidant and is a major defense system against oxidative stress. In cardiomyocytes, glutathione is particularly important (Doroshow et al., 1980). Unfortunately, after exposure to chemotherapy, glutathione in cardiomyocytes are diminished to a significant extent (Doroshow et al., 1980; Siveski-Iliskovic et al., 1995). This is probably why cardiomyocytes are more susceptible to chemotherapy than other types of cells. Third, long chain fatty acids 
are the major substrates for energy production and provide $60 \%$ to $90 \%$ of the ATP used for contraction in heart (van der Vusse et al., 1992; Ventura-Clapier et al., 2004). Cardiac hypertrophy resulting from ischemia, and infarction is associated with a metabolic switch in fuel substrates, decreasing fatty acids oxidation while increasing glucose metabolism (Iozzo et al., 2004). Coenzyme A, a membrane-associated enzyme presents on the mitochondria and endoplasmic reticulum that catalyzes the activation of long chain fatty acids. Coenzyme A is highly expressed in oxidative tissues from brown adipose tissue to heart, and depleting cardiac coenzyme A results in a $90 \%$ decrease in the mitochondrial oxidation of long chain fatty acids (Ellis et al., 2011). A cardiomyocyte specific deficiency of coenzyme A synthesis prevents the use of fatty acids for oxidation. Thus, coenzyme A deficient hearts depend on the oxidation of glucose, amino acids, and ketones for contractile energy and progressively develop cardiactoxicity (Ellis et al., 2011; Paul et al., 2014).

Thus in conclusions, our current study suggested that coenzyme complex could decrease cardiotoxicity when combined with chemotherapy in treating elderly patients with gastrointestinal cancer.

\section{References}

Alter P, Herzum M, Soufi M, et al (2006). Cardiotoxicity of 5 -fluorouracil. Cardiovasc Hematol Agents Med Chem, 4, 1-5.

Doroshow JH, Locker GY, Myers CE (1980). Enzymatic defenses of the mouse heart against reactive oxygen metabolites: alterations produced by doxorubicin. J Clin Invest, 65, 128-35.

Ellis JM, Mentock SM, Depetrillo MA, et al (2011). Mouse cardiac acyl coenzyme a synthetase 1 deficiency impairs Fatty Acid oxidation and induces cardiac hypertrophy. $\mathrm{Mol}$ Cell Biol, 31, 1252-62.

Ewer MS, Ali MK, Mackay B, et al (1984). A comparison of cardiac biopsy grades and ejection fraction estimations in patients receiving adriamycin. J Clin Oncol, 2, 112-7.

Holmes FA, Madden T, Newman RA, et al (1996). Sequencedependent alteration of doxorubicin pharmacokinetic by paclitaxel in a phase I study of paclitaxel and doxorubicin in patients with metastatic breast cancer. J Clin Oncol, 14, 2713-21.

Kaul N, Siveski-Iliskovic N, Thomas TP, et al (1995). Probucol improves antioxidant activity and modulates development of diabetic cardiomyopathy. Nutrition, 11, 551-4.

Khimji AK, Rockey DC (2010). Endothelin-biology and disease. Cell Signal, 22, 1615-25.

Kim SM, Kwak CH, Lee B, et al (2012). A case of severe coronary spasm associated with 5-fluorouracil chemotherapy. Korean J Intern Med, 27, 342-5.

Kinlay S, Behrendt D, Wainstein M, et al (2001). Role of endothelin-1 in the active constriction of human atherosclerotic coronary arteries. Circulation, 104, 1114-8.

Köhne CH, Folprecht G, Goldberg RM, et al (2008). Chemotherapy in elderly patients with colorectal cancer. Oncologist, 13, 390-402.

Kosmas C, Kallistratos MS, Kopterides P, et al (2008). Cardiotoxicity of fluoropyrimidines in different schedules of administration: a prospective study. J Cancer Res Clin Oncol, 134, 75-82.
Labianca R, Nordlinger B, Beretta GD, et al (2010). Primary colon cancer: ESMO clinical practice guidelines for diagnosis, adjuvant treatment and follow-up. Ann Oncol, 21, v70-v7.

Lamberti M, Porto S, Marra M, et al (2012). 5-Fluorouracil induces apoptosis in rat cardiocytes through intracellular oxidative stress. J Exp Clin Cancer Res, 31, 60.

Levin ER. Endothelins et al (1995). N Engl J Med, 333, 356-63.

Lipshultz SE, Rifai N, Sallan SE et al (1997). Predictive value of cardiac troponin $\mathrm{T}$ in pediatric patients at risk for myocardial injury. Circulation, 96, 2641-8.

Li T, Danelisen I, Bello-Klein A, Singal PK (2000). Effects of probucol on changes of antioxidant enzymes in adriamycininduced cardiomyopathy in rats. Cardiovasc Res, 46, 523-30.

Liu J, Huang XE, Tian GY, et al (2013). Phase II study on safety and efficacy of Yadanzi (Javanica oil emulsion injection) combined with chemotherapy for patients with gastric cancer. Asian Pac J Cancer Prev, 14, 2009-12.

Liu J, Huang XE, Feng JF (2014). Further study on pemetrexed based chemotherapy in treating patients with advanced gastric cancer (AGC). Asian Pac J Cancer Prev, 15, 6587-90.

Luwaert RJ, Descamps O, Majois F, et al (1991). Coronary artery spasm induced by 5-fluorouracil. Eur Heart J, 12, 468-70.

MacCarthy PA, Pegge NC, Prendergast BD, et al (2001). The physiological role of endogenous endothelin in the regulation of human coronary vasomotor tone. J Am Coll Cardiol, 37, 137-43.

Meydan N, Kundak I, Yavuzsen T, et al (2005). Cardiotoxicity of de Gramont's regimen: incidence, clinical characteristics and long-term follow-up. Jpn J Clin Oncol, 35, 265-70.

Meyer CC, Calis KA, Burke LB, et al (1997). Symptomatic cardiotoxicity associated with 5-fluorouracil. Pharmacotherapy, 17, 729-36.

Molyneux SL, Florkowski CM, George PM, et al (2008). Coenzyme Q10: an independent predictor of mortality in chronic heart failure. J Am Coll Cardiol, 52, 1435-41.

$\mathrm{Ng} \mathrm{M}$, Cunningham D, Norman AR (2005). The frequency and pattern of cardiotoxicity observed with capecitabine used in conjunction with oxaliplatin in patients treated for advanced colorectal cancer (CRC). Eur J Cancer, 41, 1542-6.

Ozturk MA, Ozveren O, Cinar V, et al (2013). Takotsubo syndrome: an underdiagnosed complication of 5-fluorouracil mimicking acute myocardial infarction. Blood Coagul Fibrinolysis, 24, 90-4.

Paul DS, Grevengoed TJ, Pascual F, et al (2014). Deficiency of cardiac acyl-CoA synthetase-1 induces diastolic dysfunction, but pathologic hypertrophy is reversed by rapamycin. Biochim Biophys Acta, 1841, 880-7.

Polk A, Vaage-Nilsen M, Vistisen K, et al (2013). Cardiotoxicity in cancer patients treated with 5-fluorouracil or capecitabine: A systematic review of incidence, manifestations and predisposing factors. Cancer Treat Rev, 39, 974-84.

Rezkalla S, Kloner RA, Ensley J, et al (1989). Continuous ambulatory ECG monitoring during fluorouracil therapy: a prospective study. J Clin Oncol, 7, 509-14.

Salepci T, Seker M, Uyarel H, et al (2010). 5-Fluorouracil induces arterial vasoconstrictions but does not increase angiotensin II levels. Med Oncol, 27, 416-20.

Siegel R, Naishadham D, Jemal A et al (2012). Cancer statistics, 2012. CA Cancer J Clin, 62, 10-29.

Shekelle P, Morton S, Hardy ML (2003). Effect of supplemental antioxidants vitamin C, vitamin E, and coenzyme Q10 for the prevention and treatment of cardiovascular disease. Evid Rep Technol Assess (Summ), 83, 1-3.

Shimoyama M, Murata Y, Sumi KI, et al (2001). Docetaxel induced cardiotoxicity. Heart, 86, 219. 
Shoemaker LK, Arora U, Rocha Lima CM, et al (2004). 5 -fluorouracil-induced coronary vasospasm. Cancer Control, 11, 46-9.

Siveski-Iliskovic N, Hill M, Chow DA, et al (1995). Probucol protects against Adriamycin cardiomyopathy without interfering with its antitumor effect. Circulation, 91, 10-5.

Speyer JL, Green MD, Kramer E et al (1988). Protective effect of the bispiperazinedione ICRF-187 against doxorubicininduced cardiac toxicity in women with advanced breast cancer. $N$ Engl J Med, 319, 745-52.

Speyer JL, Green MD, Zeleniuch-Jacquotte A, et al (1992). ICRF-187 permits longer treatment with doxorubicin in women with breast cancer. J Clin Oncol, 10, 117-27.

Sudhoff T, Enderle MD, Pahlke M, et al (2004). 5-Fluorouracil induces arterial vasocontractions. Ann Oncol, 15, 661-4.

Theou O, Brothers TD, Peña FG, et al (2014). Identifying common characteristics of frailty across seven scales. $J$ Am Geriatr Soc, 62, 901-6.

Thyss A, Gaspard MH, Marsault R, et al (1992). Very high endothelin plasma levels in patients with 5-FU cardiotoxicity. Ann Oncol, 3, 88.

Tsibiribi P, Bui-Xuan C, Bui-Xuan B, et al (2006). Cardiac lesions induced by 5 -fluorouracil in the rabbit. Hum Exp Toxicol, 25, 305-9.

Untch M, Rezai M, Loibl S, et al (2010). Neoadjuvant treatment with trastuzumab in HER2-positive breast cancer: results from the GeparQuattro study. J Clin Oncol, 28, 2024-31.

van der Vusse GJ, Glatz JF, Stam HC, et al (1992). Fatty acid homeostasis in the normoxic and ischemic heart. Physiol Rev, 72, 881-940.

Ventura-Clapier R, Garnier A, Veksler V (2004). Energy metabolism in heart failure. $J$ Physiol, 555, 1-13.

Wei GL, Huang XE, Huo JG, et al (2013). Phase II study on pemetrexed-based chemotherapy in treating patients with metastatic gastric cancer not responding to prior palliative chemotherapy. Asian Pac J Cancer Prev, 14, 2703-6.

Xu X, Wang L, Xu HQ, et al (2013). Clinical comparison between paclitaxel liposome (Lipusu) and paclitaxel for treatment of patients with metastatic gastric cancer. Asian Pac J Cancer Prev, 14, 2591-4.

Yancik R (1997). Cancer burden in the aged: an epidemiologic and demographic overview. Cancer, 80, 1273-83. 